\title{
KEBERADAAN OVARIUM TRANSLUCENT SEBAGAI INDIKATOR MUSIM PEMIJAHAN IKAN LEMA Rastrelliger kanagurta (Cuvier, 1816) DI TELUK MAYALIBIT KEPULAUAN RAJAAMPAT
}

\section{THE OCCURRENCE OF TRANSLUCENT OVARIES AS INDICATOR OF PEAK SPAWNING SEASON OF INDIAN MACKEREL Rastrelliger kanagurta (Cuvier, 1816) IN MAYALIBIT BAY RAJA AMPAT ISLANDS}

\author{
Dian Oktaviani ${ }^{1}$, Bertha Matatar ${ }^{2}$ dan Duto Nugroho ${ }^{1}$ \\ ${ }^{1}$ Pusat Penelitian Pengelolaan Perikanan dan Konservasi Sumber Daya Ikan \\ ${ }^{2}$ Conservation International Raja Ampat Program \\ Teregistrasi I tanggal: 10 Juli 2014; Diterima setelah perbaikan tanggal: 30 Maret 2015; \\ Disetujui terbit tanggal: 06 April 2015 \\ e-mail: dianoktavianni@gmail.com
}

\begin{abstract}
ABSTRAK
Tersedianya data dan informasi tentang musim pemijahan merupakan salah satu komponen biologi yang berperan penting bagi perlindungan sedian induk dalam rangka menjamin kelangsungan sumber daya ikan secara berkelanjutan. Ikan Lema merupakan ikan pelagis kecil yang termasuk dalam Genus Rastrelliger dengansifat reproduksinya dikelompokkan sebagai partial spawner. Kelompok jenis ini sulit untuk ditentukan puncak musim pemijahannya karena tingkat kematangan sexual IV ditemukan setiap bulan. Oleh karena itu, suatu upaya penelitian telah dilakukan untuk mengetahui karakteristik ovarium tingkat IV dan hasilnya dapat dijadikan indikator yang ditujukan untuk menentukan puncak musim pemijahan jenis ikan Lema yang tergolong sebagai partial spawner. Ikan lema Rastrelliger kanagurta (Cuvier, 1816) merupakan hasil tangkapan utama nelayan di Teluk Mayalibit yang beroperasi dengan perahu tanpa motor yang dilengkapi dengan lampu pada periode gelap bulan. Pengukuran dilakukan pada kurun waktu bulan Maret 2011 sampai dengan Februari 2012. Pengamatan terhadap sejumlah 656 specimen ovarium tingkat IV dengan rerata 55 spesimen/bulan) yang telah dikumpulkan pada periode tersebut. Analisis makroskopik difokuskan terhadap gonad betina (ovarium) pada tingkat IV yang diklasifikasikan sebagai ovarium translucent. Hasil analisis menunjukkan bahwa nilai frekuensi sampel bulanan terhadap ovarium translucent (51 - 100\% hydrated oocyte) memperlihatkan bahwa puncak musim pemijahan terjadi pada September $(15,4 \%$ dan 24,0 \%), Oktober (12,8 dan 9,4\%), dan November (17,9\% dan 13,2 \%). Temuan ini memberikan indikasi nyata bahwa tingginya frekuensi kejadian ovarium translucent dapat dijadikan indikator penentuan puncak musim pemijahan.
\end{abstract}

KATA KUNCI: Pemijahan, ovarium translucent, Rastrelliger kanagurta, Raja Ampat

\begin{abstract}
The availability of data and information on spawning season is one biological component plays an important role for the protection of spawning biomass that would ensure sustainability of fish resources. Lema fish as small pelagic fish belong to genus Rastrelliger that classified as partial spawner. This typical spawners mostly difficult to determine their peak spawning season due to the mature specimens (stage IV) occurred in monthly bases. Research effort has been undertaken on maturity characteristics of stage IV of ovaries with aimed to derive an indicator to determine the peak spawning season for this lema species. Lema fish Rastrelliger kanagurta (Cuvier, 1816) are the main catches of fishermen in the Gulf Mayalibit operated by using small dug boat with lighting during the dark moon period. Monthly collection was conducted during the period March 2011 to February 2012. Observation were carried out to 656 of mature ovaries specimens with a mean of 55 specimens/month that has been collected during the period. The macroscopic analysis is focused on mature ovaries (stage IV) with specific condition of translucent ovaries. The result showed that the frequency of monthly samples of translucent ovaries (51-100\% hydrated oocyte) indicated the peak of the spawning season occurs in September (15.4\% and 24.0\%), October (12.8\% and 9.4\%), and November (17.9\% and $13.2 \%)$. These findings provide a clear indication that the high frequency of occurrence of translucent ovaries could play as an indicator in determining the peak spawning season of lema fish in the area of interest.
\end{abstract}

KEYWORDS: Spawning, Rastrelliger kanagurta, translucent ovary, Raja Ampat 


\section{PENDAHULUAN}

Ikan lema merupakan sumberdaya ikan yang menjadi hasil tangkapan utama nelayan di Teluk Mayalibit diidentifikasi sebagai Rastelliger kanagurta (Cuvier, 1816) (Oktaviani et al., 2012). Cara penangkapan dilakukan melalui teknik penangkapan tradisonal yang disebut "balobe lema". Sistem operasi dilakukan pada periode gelap bulan, menggunakan perahu tanpa motor yang dilengkapi lampu yang berfungsi sebagai alat bantu pengumpul ikan. Hasil tangkapan terkumpul kemudian dipilih dengan batasan Ikan yang berukuran panjang cagak (fork length) sekitar $20 \mathrm{~cm}$ merupakan target utama yang dipasarkan, sedangkan ikan yang berukuran lebih kecil dilepaskan dalam keadaan hidup, Pengetahuan tentang aspek reproduksi untuk prediksi musim pemijahan ikan merupakan salah satu komponen utama yang berperan dalam menjaga keberlanjutan sumberdaya ikan. Prediksi musim berpijah dapat dilakukan melalui pengamatan frekuensi kejadian specimen dengan tingkat kematangan gonad (TKG) IV (Atmadja 1994). Selain itu perkiraan musim pemijahan dapat juga diduga melalui pengukuran Gonadal-Somatic Index (GSI) (Davies, 1956 dalam Hunter \& Machewich, 1985). Karakteristik pemijahan yang digolongkan ke dalam partial spawner sering kali menyulitkan penentuan musim pemijahan. Hal itu dikarenakan karakteristik partial spawner yang didefinisikan sebagai pola pemijahan yang berlangsung sepanjang tahun dengan ovari yang dalam tahap pematangan ditemukan semua tahapan perkembangan ovum. Menurut Holden \& Raitt (1974), genus Rastrelliger dikelompokkan ke dalam jenis ikan yang bersifat partial spawner.

Kegiatan penangkapan yang intensif dapat mengakibatkan penangkapan berlebih (overfishing) yang berdampak pada penurunan populasi $R$. kanagurta di Teluk Mayalibit. Upaya pengelolaan perikanan $R$. kanagurta di Teluk Mayalibit memerlukan kajian ilmiah yang cukup terutama terkait dengan penentuan musim pemijahannya. Tulisan ini ditujukan untuk menggambarkan peran keberadaan ovarium translucent untuk memperkuat penentuan puncak musim pemijahan berdasarkan nilai GSI dan frekuensi kejadian specimen matang gonada pada kelompok ikan partial spawner. Hasil diharapkan dapat menjadi dasar penentuan periode yang tepat untuk dilakukan pengelolaan berdasarkan pertimbangan pembatasan waktu dan jumlah tangkapan.

\section{BAHANDANMETODE \\ Waktu dan Lokasi}

Penelitian dilakukan mulai dari Maret 2011 sampai dengan Februari 2012. Lokasi penelitian adalah di Kampung Warsambin yang terletak pada posisi $\left(00^{\circ} 19,068^{\prime}\right.$ LS; $130^{\circ} 55,168^{\prime}$ BT) dan Kampung Lopintol ( $00^{\circ} 18,897^{\prime} \mathrm{LS}$; $130^{\circ} 53,475^{\circ} \mathrm{BT}$ ) yang terletak di pesisir Teluk Mayalibit dalam wilayah Kabupaten Raja Ampat, Papua Barat (Gambar 1). Peraturan Bupati nomor 66 tahun 2007 menetapkan bahwa Teluk Mayalibit dengan luas sebesar 34.000 ha sebagai kawasan konservasi.

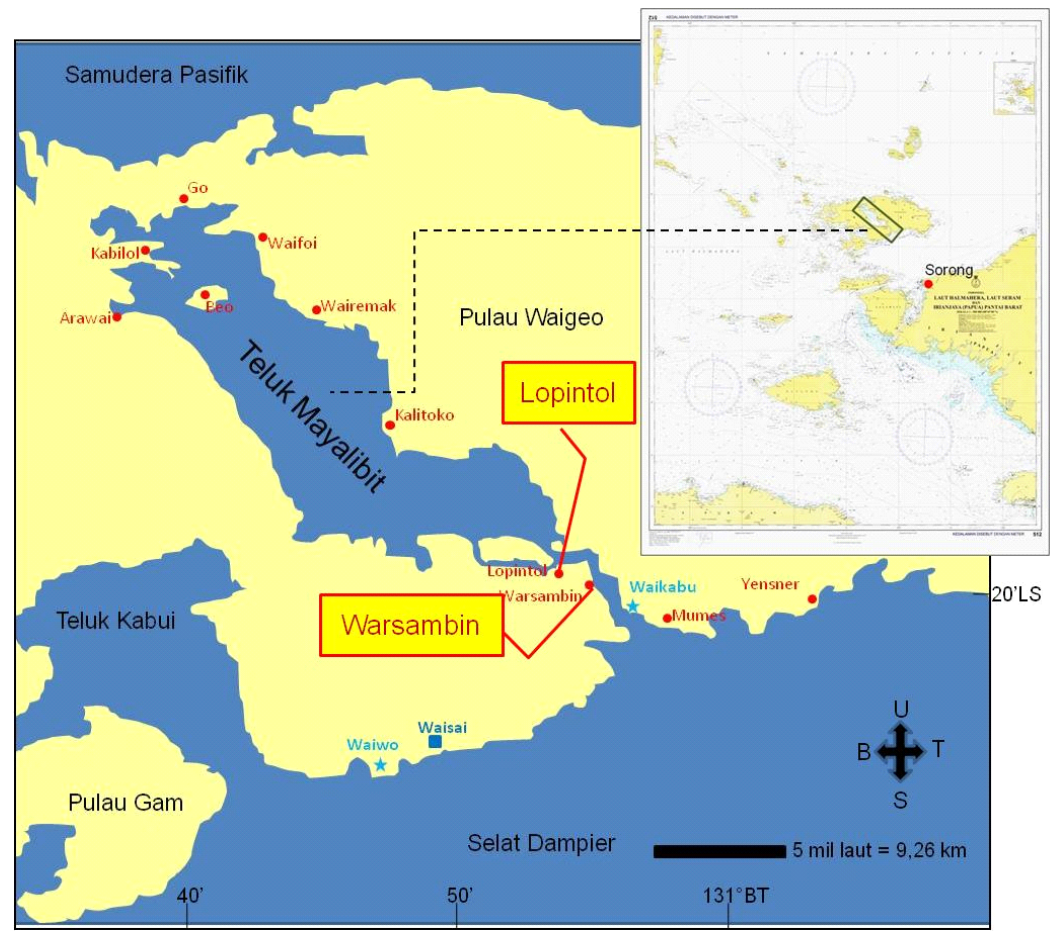

Gambar 1. Lokasi penelitian ikan Lema di Kepulauan Raja Ampat (modifikasi peta Dishidros 1996).

Figure 1. Field study of Indian Makerel in Raja Ampat island (modified from Dishidros 1996). 


\section{Pengambilan Sampel Ikan}

Populasi $R$. kanagurta yang ditangkap oleh nelayan dari Kampung Warsambin dan Kampung Lopintol diasumsikan sebagai satu populasi. Pengambilan sampel dilakukan sepanjang periode penangkapan yang berlangsung selama 3 minggu setiap bulan selama 12 bulan. Sampel yang menjadi tujuan pengamatan untuk penentuan musim pemijahan berukuran dewasa (e" $20 \mathrm{~cm}$ ). Ukuran panjang tubuh yang digunakan berdasarkan pada panjang cagak (fork length). Ikan-ikan tersebut disimpan sementara di dalam cool box yang berisi es batu, kemudian dipindahkan ke dalam lemari es untuk menjaga kesegaran sampel. Penyimpanan dilakukan tidak lebih dari 12 jam.

\section{Pengukuran Panjang dan Berat}

Spesimen dipisahkan berdasarkan perbedaan kelamin. Panjang tubuh ikan dilakukan dengan mencatat panjang cagak (fork length) di atas papan ukur dengan ketelitian satu desimal $(0,1)$ berdasarkan pada satuan sentimeter $(\mathrm{cm})$. Berat tubuh dan berat gonad diamati melalui penimbangan ikan atau gonad dengan ketelitian satu desimal $(0,1)$ berdasarkan pada satuan gram $(\mathrm{g})$.

\section{Pengamatan Gonad}

Gonad yang diamati difokuskan pada gonad betina (ovarium), namun tidak meninggalkan gonad jantan (testis). Pengamatan dilakukan secara visual (makroskopis) dengan lima tingkat kematangan gonad (TKG). Masing-masing TKG ditentukan berdasarkan ciri-ciri yang dikemukakan oleh Holden \& Raitt (1974). Gonad diamati setelah tubuh ikan dibedah pada bagian abdomen dan dikeluarkan dari rongga perut. Gonad selanjutnya ditimbang dan dicatat beratnya. Pengamatan makroskopis terhadap ovarium translucent ditentukan dari sebaran jumlah persentase ovum translucent (hydrated oocyte). Ovarium translucent merupakan ovarium yang berisikan 25-100\% ovum translucent (hydrated oocyte) yang dianggap sebagai ovarium matang oleh Atmadja (1994). Kondisi ovarium translucent dengan $100 \%$ hydrated oocyte ditunjukkan pada Gambar 2. Jumlah ovarium translucent yang ditemukan dicatat setiap bulan. Ovarium translucent dibedakan menjadi 3 kategori berdasarkan persentase jumlah ovum translucent (hydrated oocyte) dari ovarium secara makroskopis. Ketiga kategori itu yang dideskripsikan sebagai berikut:

a. Ovarium yang berisikan $25 \%$ hydrated oocyte;

b. Ovarium yang berisikan 26-50\% hydrated oocyte; dan

c. Ovarium yang berisikan $51-100 \%$ hydrated oocyte.
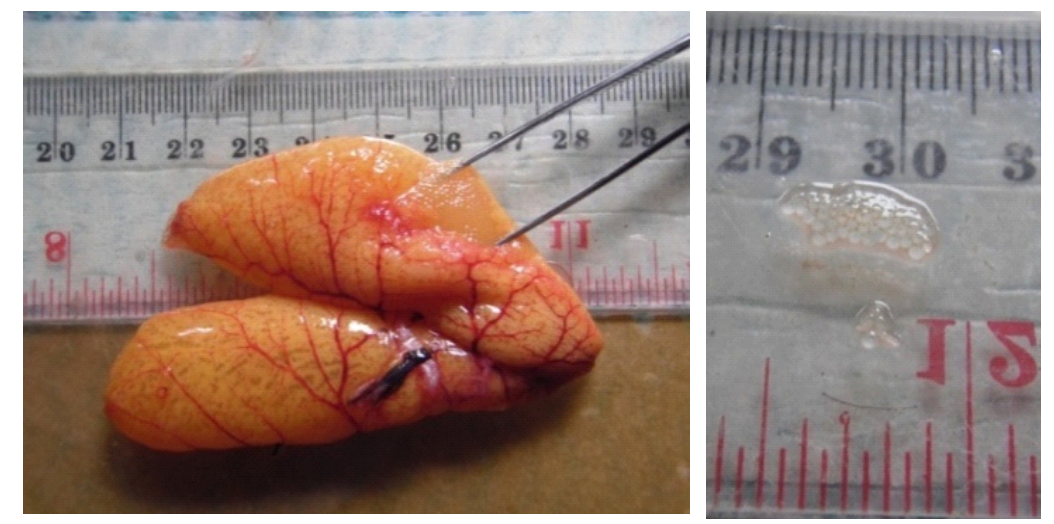

Gambar 2. Ovarium translucent dengan $100 \%$ ovum translucent (A) dan ovum translucent (B) dari sampel R. kanagurta di Teluk Mayalibit. (Foto: Dian Oktaviani 2011).

Figure 2. Translucent ovarium with $100 \%$ ovum translucent (A) and translucent ovum (B) of R. kanagurta in Mayalibit Bay. (Photos: Dian Oktaviani 2011).

\section{Analisis Data}

Penentuan musim pemijahan dilakukan dengan menganalisis data dari sampel ovarium. Analisis data menggunakan persamaan umum di dalam menentukan musim pemijahan, yaitu:

Frekuensi jumlah ovarium TKG IV dari semua fase TKG (Merta, 1992) yang mengikuti persamaan sebagai berikut:

$$
\frac{\sum \text { ovarium TKG IV }}{\sum \text { ovarium TKG1-V }} X 100 \%
$$

Gonadal-Somatic Index (GSI) pada TKG IV dihitung dengan persamaan yang digunakan pada penelitian Zamroni et al. (2008) sebagai berikut:

$$
G S I=\frac{W g}{W b} X 100
$$

dengan:

$\mathrm{Wg}$ : berat ovari segar, gram

$\mathrm{Wb}$ : berat total ikan, gram

Analisis data sampel ovarium translucent digunakan dua persamaan yang masing-masing diformulasikan berdasarkan persamaan (1), sebagai berikut: 
Frekuensi ovarium translucent dari total sampel ovarium translucent. dihitung melalui persamaan sebagai berikut:

$$
\frac{\sum O T i}{\text { OTn }} X 100 \%
$$

dengan:

OTn : total sampel ovarium translucent selama 12 bulan

Frekuensi ovarium translucent dari sampel ovarium TKG IV setiap bulan. dihitung dengan menggunakan persamaan sebagai berikut:

$$
\frac{\sum O T i}{O M i} X 100 \%
$$

\section{dengan:}

OTi : sampel ovarium translucent per bulan

OMi : sampel ovarium TKG IV per bulan
Hasil yang didapatkan dari masing-masing persamaan disajikan dalam bentuk grafik. Analisis grafik dijabarkan secara deskriptif berdasarkan pada fenomena yang ditemukan.

\section{HASIL DAN BAHASAN \\ HASIL}

Hasil perhitungan dengan menggunakan persamaan (1) dan persamaan (2) diperlihatkan pada Gambar 3. Frekuensi jumlah spesimen dengan TKG IV yang diturunkan dari persamaan (1) yang diperlihatkan pada Gambar 3 ditemukan bahwa specimen dengan ovarium TKG IV ditemukan setiap bulan, sehingga memberikan indikasi bahwa terjadi pemijahan sepanjang tahun. Persamaan (1) juga memperlihatkan bahwa puncak musim pemijahan terjadi pada Februari (67,89\%), Maret (55,10\%), dan April $(50,62 \%)$, Sedangkan persentase TKG IV terendah ditemukan pada Agustus 2011 (23,26\%), dan tertinggi pada Februari 2012 (67,89\%).

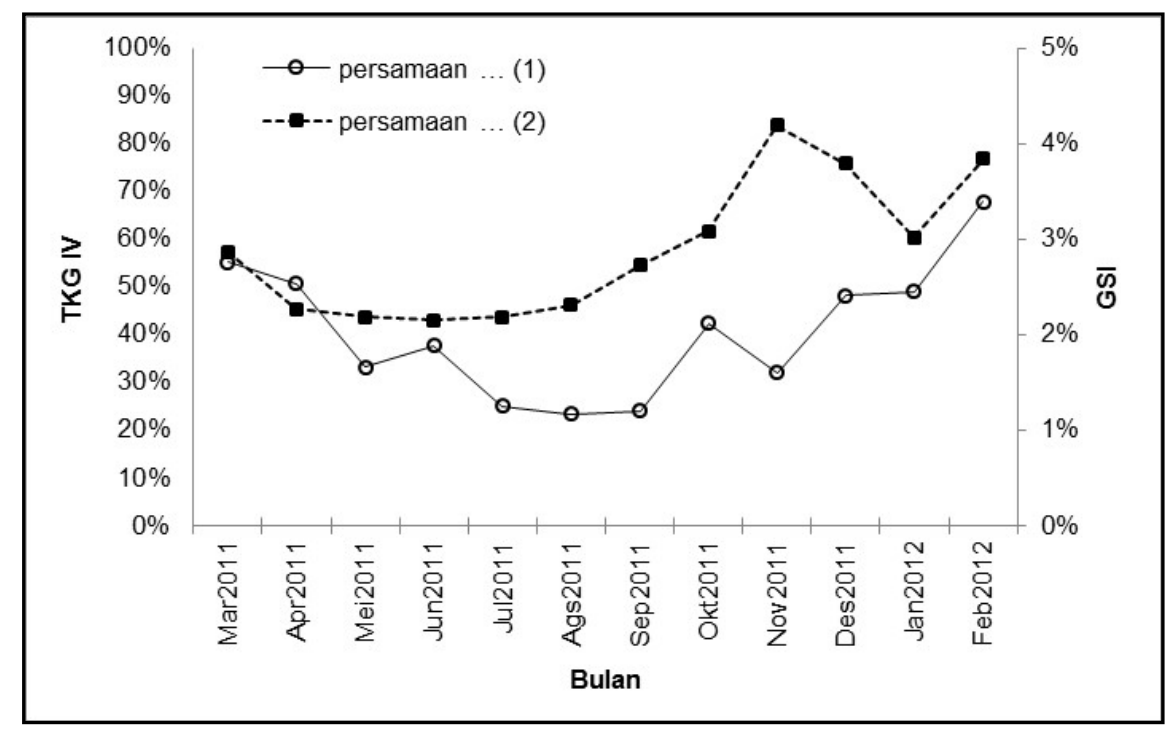

Gambar 3. Pola musim pemijahan R. kanagurta di Teluk Mayalibit.

Figure 3. Trend of spawning season of R. kanagurta in Mayalibit Bay.

Perhitungan GSI berdasarkan persamaan (2) memperlihatkan bahwa rata-rata nilai GSI dari sampel ovarium TKG IV yang didapatkan setiap bulan. Nilai GSI bulanan yang didapatkan antara $2,15-4,19 \%$ yang berasal dari nilai GSI per sampel antara $0,90-14,48 \%$. Nilai GSI bulanan terendah ditemukan pada Juni 2011, sedangkan yang tertinggi ditemukan pada November 2011. Pola grafik Gambar 3 memperlihatkan bahwa musim pemijahan terjadi antara Februari - April dan September - November.

Hasil pengukuran selama periode Maret 2011 hingga Februari 2012 menunjukkan bahwa terdapat satu indikator lain yang dapat dijadikan sebagai indikator musim pemijahan. Indikator itu adalah keberadaan ovarium translucent. Sampel ikan yang memiliki ovarium translucent sebanyak 39 ekor dari total sampel ikan betina dengan ovarium TKG IV sebanyak 687 ekor. Ikan dengan ovarium translucent ditemukan selama 10 bulan dari Mei 2011 - Februari 2012. Berdasarkan persamaan (3) yang dideskripsikan pada Gambar 4 memperlihatkan bahwa sampel ikan dengan ovarium translucent paling banyak ditemukan pada November 2011 yaitu 9 ekor dari 39 ekor $(23,1 \%)$, sedangkan Maret dan April 2011 tidak ditemukan sama sekali. Ovarium translucent dengan 51-100\% hydrated oocyte ditemukan dari Mei 2011- Februari 2012 dengan persentase antara 2,6-17,9\%. 


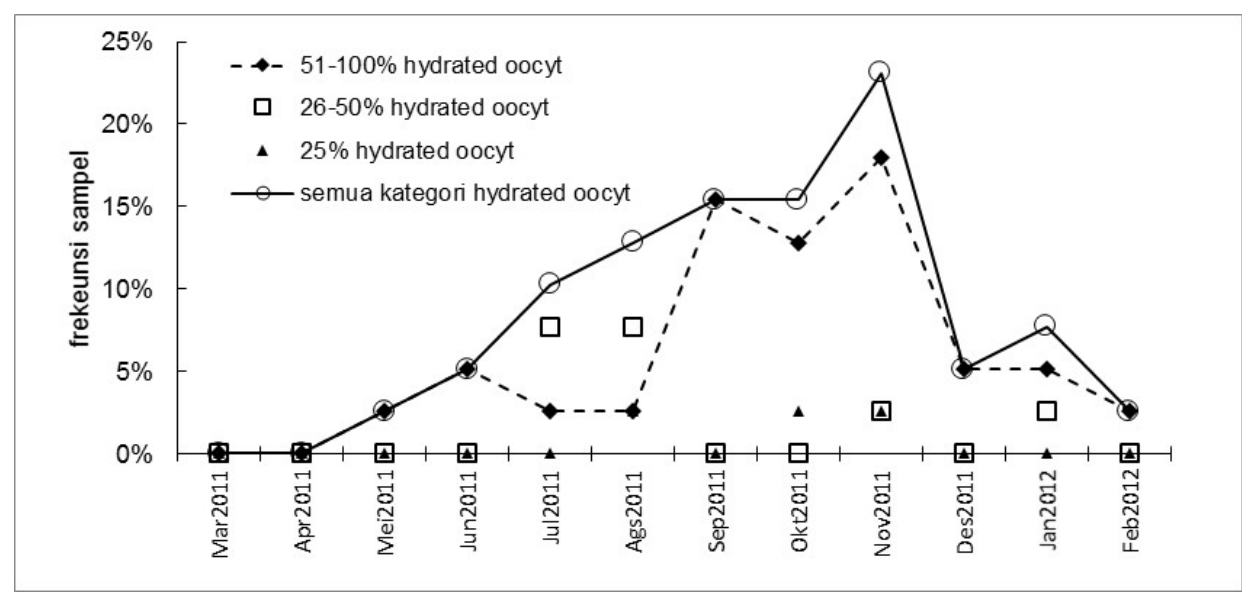

Gambar 4. Sebaran frekuensi bulanan ovarium translucent berdasarkan persamaan (3).

Figure 4. Distribution of translucent ovaries frequency base on formula (3), monthly.

Frekuensi kejadian ovarium translucent dari sampel ovarium TKG IV setiap bulan yang dideskripsikan pada Gambar 5 memperlihatkan bahwa sampel ikan dengan ovarium translucent paling banyak ditemukan pada September 2011 yaitu 6 ekor dari 25 ekor sampel ikan betina TKG IV (24,0\%). Frekuensi ovarium translucent dengan
$51-100 \%$ hydrated oocyte dari sampel ikan betina TKG IV setiap bulan ditemukan dari bulan Mei 2011 - Februari 2012 dengan persentase antara $0,9-24,0 \%$. Sampel ovarium translucent bulan September yang berasal dari 6 ekor ikan sampel merupakan ovarium yang mengandung $51-100 \%$ hydrated oocyte.

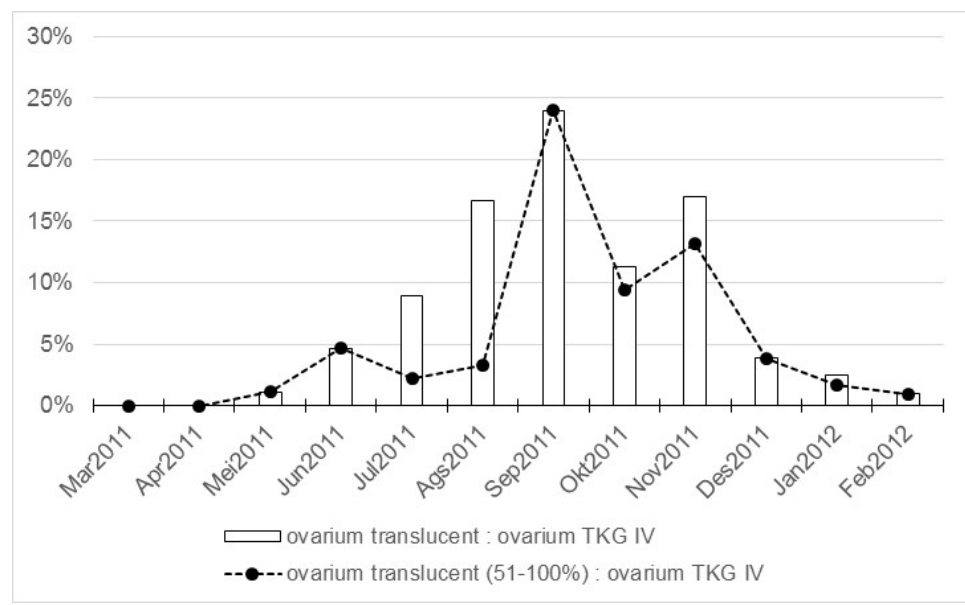

Gambar 5. Sebaran frekuensi ovarium translucent bulanan berdasarkan persamaan (4).

Figure 5. Monthly distribution of translucent ovaries frequency base on formula (4).

\section{BAHASAN}

Penentuan musim pemijahan dilandaskan pada kondisi gonad betina (ovarium) karena berhubungan erat dengan mekanisme fertilisasi yang akan menghasilkan sejumlah juvenil. Selain itu, pengamatan in-situ secara makroskopis (visual) terhadap ovarium lebih mudah daripada testis. Hasil penelitian Oktaviani (2013) terhadap R. kanagurta di Teluk Mayalibit menyatakan bahwa pola bulanan nilai GSI ovarium TKG IV diikuti oleh pola nilai GSI testis TKG IV yang sama. Menurut Miller \& Kendall (2009) bahwa ketika betina menginvestasikan energi yang besar untuk menghasilkan ovum, maka jantan juga akan mengimbanginya untuk menghasilkan sperma yang menjamin untuk terjadi fertilisasi.

Secara umum, indikator yang digunakan untuk menentukan musim pemijahan adalah frekuensi gonad (Merta, 1992; Hariati et al., 2005) dan nilai Gonad Somatic Index, GSI (Zamroni et al., 2008; Wudji et al., 2013) dari ovarium TKG IV. Pola grafik pada Gambar 3 membuktikan bahwa terjadi pemijahan sepanjang tahun dengan dua musim pemijahan yaitu Februari - April dan September November. Fenomena itu juga dinyatakan oleh Hariati et al. (2005) bahwa musim pemijahan $R$. kanagurta di Selat Malaka terjadi dua musim yaitu Januari - Maret dan Mei - 
Oktober. Apabila ditinjau dari nilai puncak didapatkan nilai yang berbeda. Oleh karena itu, dua musim pemijahan tersebut dapat dibedakan terdiri atas: musim pemijahan bayangan dan musim pemijahan utama (puncak musim pemijahan).

Pendugaan musin pemijahan berdasarkan frekuensi kejadian specimen dengan tingkat kematangan IV dan nilai GSI yang tinggi belum dapat memastikan puncak musim pemijahan yang sebenarnya. Hal ini karena hasil perhitungan melalui persamaan (1) memperlihatkan puncak musim pemijahan terjadi pada Februari - April, sedangkan persamaan (2) terjadi pada September November. Perbedaan ini disebabkan oleh indikator yang digunakan berbeda yaitu jumlah ovarium TKG IV dan berat ovarium TKG IV. Selain itu, jumlah ovarium TKG IV dipengaruhi oleh jumlah ovarium TKG IV yang sudah salin (dipijahkan) sebagian masih memiliki karakteristik sebagai TKG IV. Demikian juga nilai GSI karena ditemukan nilai GSI yang rendah dari sampel ovarium TKG IV yaitu 0,90\% (berat: 1,5 g). Oktaviani et al. (2014) dan Oktaviani (2013) melaporkan ovarium translucent dengan nilai GSI 2,06 \% (berat: 3,1 g) dari sampel ikan berukuran panjang cagak 22,0 cm dengan berat 150,4 g. Nilai GSI terendah ovarium TKG III dan TKG IV R. kanagurta di Laut Banda masing-masing adalah 0,80\% dan 2,51\% (Zamroni \& Suwarso, 2011). Meskipun demikian, nilai yang didapatkan dari persamaan (2) lebih mendekati daripada persamaan (1) di dalam penentuan puncak musim pemijahan. Hal itu disebabkan oleh semakin mendekati musim pemijahan akan semakin banyak ditemukan ovarium TKG IV, sehingga nilai GSI akan semakin meningkat. Nilai GSI akan semakin meningkat seiring dengan perkembangan kematangannya (Holden \& Raitt, 1974); Suryati et al., (2014).

Pola grafik berdasarkan persamaan (2) memperlihatkan pola yang menyerupai pola grafik pada persamaan (3). Grafik tersebut menunjukkan bahwa pada bulan September, Oktober, dan November 2011 didapatkan sampel ikan dengan ovarium translucent yang berisikan 50-100\% hydrated oocyte lebih banyak yaitu $5-7$ ekor, sedangkan sembilan bulan lainnya sejumlah $1-2$ ekor. Adapun pola grafik dari persamaan (3) dan persamaan (4) memperlihatkan bahwa terdapat satu musim pemijahan yang berawal dari Mei 2011 - Februari 2012. Puncak musim pemijahan terjadi pada September, Oktober, dan November berdasarkan frekuensi ovarium translucent dengan 51 $100 \%$ hydrated oocyte. Heyman et al. (2004) menyatakan bahwa keberadaan ovarium translucent (hydrated oocytes) dapat dijadikan indikator terbaik dari suatu fish spawning aggregation (sekumpulan ikan yang siap memijah). Hydrated oocytes merupakan fase terakhir dari perkembangan ovum untuk siap dibuahi (fertilisasi). Selama dilakukan pembedahan terhadap sampel ikan dengan ovarium dengan $100 \%$ hydrated oocyte maka saat bagian abdomen ditekan akan keluar hydrated oocyte dari saluran indung telur (aperture of oviduct). Oleh karena itu, apabila pada bulan tertentu paling banyak ditemukan ovarium translucent maka dapat diasumsikan bahwa bulan tersebut sebagai puncak musim pemijahan.

\section{KESIMPULAN}

Puncak musim pemijahan $R$. kanagurta dapat ditentukan berdasarkan pola nilai GSI yang diperkuat dengan frekuensi jumlah ovarium translucent setiap bulan. Kondisi makroskopis ovarium translucent terbaik yang dijadikan indikator adalah ovarium yang berisikan $51-100 \%$ hydrated oocyte. Puncak musim pemijahan $R$. kanagurta di Teluk Mayalibit dipastikan terjadi pada September, Oktober, dan November.

\section{PERSANTUNAN}

Tulisan ini merupakan data penelitian yang didanai dan difasilitasi oleh Conservation International Indonesia (CII) pada Fiscal Year (FY) 2010/2011 dan 2011/ 2012. Beberapa peralatan laboratorium difasilitasi oleh Pusat Penelitian Pengelolaan Perikanan dan Konservasi Sumber Daya Ikan (P4KSI). Ucapan terima kasih secara khusus kepada Tim KKPD Teluk Mayalibit, nelayan, dan masyarakat serta Dinas Kelautan dan Perikanan Kabupaten Raja Ampat yang telah membantu selama masa pengumpulan data di lapangan.

\section{DAFTAR PUSTAKA}

Atmadja, S.B. 1994. Tingkat Kematangan Gonad beberapa ikan pelagis kecil dari Laut Jawa. J. Lit. Perikan. Ind. 92: 1-8.

Hariati, T., M. Taufik \& A. Zamroni. 2005. Beberapa aspek reproduksi ikan layang (Decapterus russelli) dan ikan banyar (Rastrelliger kanagurta) di perairan Selat Malaka Indonesia. J. Lit. Perikan. Ind. 11 (2): 47-57.

Heyman, W., J. Azueta, O. Lara, I. Majil, D. Neal, B. Luckhurst, M. Paz, I. Morrison, K.L. Rhodes, B. Kjerve, B. Wade \& N. Requena. 2004. Spawning aggreration monitoring protocol for the Meso-American Reef and the Wider Caribean. Version 2.0. Meso-American Reef System Project, Belize: $55 \mathrm{hlm}$.

Holden, M.J. \& D.F.S. Raitt (eds.). 1974. Manual of fisheries sciences. Part 2. Methods of resource investigation and their application. FAO Fisheries.

Hunter R.O. \& B. Macewicz. 1985. Measurement of Spawning Frequency in Multiple Spawning Fishes dalam Lasker R. (eds) An Egg Production Method for Estimating Spawning Biomass of Pelagic Fish: 
Application tothe Northern Anchovy, Engraulis mordax. NOAA Technical Report NMFS 36.

James, P.B.R. \& V. M. Baragi. 1980. Ovary as an Indicator of Frequency of Spawning in Fishes. Proc. Indian Nat. Sci. Acad. B 46 (4): 479-489.

Merta, I.G.S. 1992. Dinamika populasi ikan lemuru, Sardinella lemuru Bleeker 1853 (Pisces: Clupeidae) di perairan Selat Bali dan alternatif pengelolaannya. Disertasi. Institut Pertanian Bogor, Bogor: xvi + 201 p.

Miller, B.S. \& A.W. Kendall Jr. 2009. The early life history of marine fishes. University of California Press, Oakland: $\mathrm{xi}+376$.
Oktaviani, D. 2013. Etnozoologi, biologi reroduksi, dan pelestarian ikan lema Ratrelliger kanagurta (Cuvier, 1816) di Teluk Mayalibit Kabupaten Raja Ampat Papaua Barat Indonesia. Disertasi. Program Studi Biologi. Program Pascasarja. Fakultas Matematika dan Ilmu Pengetahuan Alam. Universitas Indonesia. Depok: xi $+128 \mathrm{p}$.

Oktaviani, D., J. Supriatna, M.V. Erdmann \& Abinawanto. 2014. Maturity stages of Indian mackerel Rastrelliger kanagurta (Cuvier, 1817) in Mayalibit Bay, Raja Amapat, West Papua. Int. J. Aqu. Sci. 5 (1): 67 - 76.

Suryati, N. K., S. Makmur \& S. Nurdawati. 2014. Biologi repoduksi ikan sumpit (Toxotes microlepis Gunther 1860) di perairan Sungai Musi Sumatera Selatan. Bawal. 63): $119-126$.

Wudji, A., Suwarso \& Wudianto. 2013. Biologi reproduksi dan musim pemijahan ikan lemuru (Sardinella lemuru Bleeker 1853) di perairan Selat Bali. Bawal 5 (1): 49 -57.

Zamroni, A., Suwarso \& N.A. Mukhlis. 2008. Biologi reproduksi dan genetik populasi ikan kembung (Rastrelliger brachysoma, Famili scombridae) di Pantai Utara Jawa. J. Lit. Perikan. Ind. 14 (2): 215-226.

Zamroni \& Suwarso. 2011. Studi tentang bagi reprodusi beberapa spesies ikan pelagis kecil di perairan Laut Banda. Bawal. 3 (5): 337-344. 